\title{
PARQUE LINEAR EM BATAGUASSU/MS COMO PAISAGEM, PLANEJAMENTO E CONTROLE URBANOS
}

\author{
Brysa Yanara de Mendonça Thomazini ${ }^{1}$, Sibila Corral de Arêa Leão Honda ${ }^{2}$ \\ ${ }^{1}$ Discente do curso de Arquitetura e Urbanismo da Universidade do Oeste Paulista. ${ }^{2}$ Docente e Coordenadora do \\ curso de Arquitetura e Urbanismo da Universidade do Oeste Paulista
}

\section{RESUMO}

A expansão territorial urbana no Brasil tem proporcionado ocupação de diversas áreas ambientalmente frágeis, em processo de degradação do meio ambiente. Ao contrário desse processo, parques urbanos têm sido projetados e implantados junto a rios e córregos, estimulando sua preservação. Este artigo é resultado de estudos e proposta de projeto de parque linear no Córrego Guassu, na cidade de Bataguassu, no Estado de Mato Grosso do Sul. Visa-se à preservação do córrego, à oferta de espaço público de lazer adequado à sua população, e ao controle da expansão da malha urbana dessa cidade. A metodologia utilizada na pesquisa foi baseada em aprofundamento teórico e projetual.

Palavras-chave: parque linear; planejamento ambiental urbano; preservação ambiental; lazer; controle urbano.

\section{INTRODUÇÃo}

Este artigo é resultado de pesquisa elaborada na disciplina de Trabalho de Conclusão de Curso I, do curso de Arquitetura e Urbanismo na Universidade do Oeste Paulista, cujo tema é a recuperação de córrego junto à malha urbana de Bataguassu-MS, visando à ocupação e utilização sustentável de seu entorno e preservação das áreas mais frágeis ambientalmente.

Para tal, buscou-se identificar e separar regiões para usos diferenciados por meio do conceito de zoneamento ambiental, resultando na criação de um Parque Linear no Córrego Guassu, visto que parques lineares apresentam características diferenciadas de um parque convencional, principalmente porque resulta de associação à rede hídrica fluvial. Nesse sentido, é fundamental integrá-lo ao ambiente natural, com continuidade a caminhos verdes e à cobertura vegetal e arborização ao longo do curso hídrico.

O objetivo principal do parque proposto neste trabalho é unir área verde e recreação em um mesmo lugar, pois com isso a população tomaria conhecimento da importância da área de intervenção e sua preservação, visto que essa importância é percebida quando se agrega a esses espaços equipamentos públicos que geram para a população espaços esportivos e recreativos.

O bairro Jardim América III, loteado em Bataguassu há pouco tempo, encontra-se crescendo no sentido do córrego Guassu, desencadeiando um aglomerado de problemas para o meio ambiente e para a população que reside nesse bairro, problemas com erosões e cheias são 
as mais frequentes, impossibilitando o transito dos moradores nas ruas em dias de chuva. A criação do Parque Linear objetiva também bloquear o crescimento do bairro ocupando as margens do córrego.

Importante destacar também que a cidade de Bataguassu apresenta ausência de espaços de recreação e lazer em áreas naturais. Esess, quando são criados, servem de atrativo para a população, como espaços adequados para fins de atividades que proporcionem o encontro das pessoas, de contemplação e de uso do verde, permitindo que os moradores da cidade estejam em contato direto com a natureza, fazendo que notem o parque como pertencente a eles, e que merece ser preservado, agregando assim uma maior qualidade na vida das pessoas.

\section{METODOLOGIA}

A metodologia utilizada nesta pesquisa está baseada em aprofundamento teórico, levantamento ambiental e urbanístico da área, compreensão sobre parques com preservação ambiental e suas possíveis utilizações, análises das leis ambientais federais, estaduais e municipais, e identificação e estudos de antecedentes projetuais existentes.

\section{PARQUES URBANOS}

Pode-se conceituar praças e parques atuais como locais públicos e abertos, de passagem e de permanência, com vegetação, mobiliário urbano, presença de atrativos como brinquedos infantis e academia voltadas para idosos que também vem sendo inserida para chamar a população a usufruírem do espaço público, e dar qualidade e vitalidade aos mesmos, proporcionando aos moradores da cidade locais de recreação e convívio democratizado.

Afirma Guzzo (1991, apud SILVA et al, 2008, p.05):

As áreas verdes urbanas proporcionam melhorias no ambiente excessivamente impactado das cidades e benefícios para os habitantes das mesmas. A função ecológica deve-se ao fato da presença da vegetação, do solo não impermeabilizado e de uma fauna mais diversificada nessas áreas, promovendo melhorias no clima da cidade e na qualidade da água e do solo.

Esses espaços inseridos na cidade podem ser de grande atrativo e melhoria para bairros onde estão localizados, se bem cuidados, com iluminação adequada, manutenção realizada diariamente, e conservação de equipamentos públicos, podem modificar o ambiente onde estão, deixando o espaço agradável e a permanência no mesmo prazerosa. 
Porém, se forem deixados de lado, sem manutenção ou inseridos em locais onde não tenham uso e passagem de pessoas, estão condenados ao fracasso pelo desuso, podendo-se tornar locais de vandalismos e pontos de criminalidade, deixando a população que reside próximo a eles insegura, não fazendo uso do ambiente, deixando o lugar com pouca vitalidade, interferindo assim na paisagem da cidade.

\subsection{PAQUE LINEAR EM BATAGUASSU-MS}

Bataguassu é uma cidade da região leste do estado de Mato Grosso do Sul e está inserida na bacia hidrográfica do Rio Paraná. Foi fundada em 11 de dezembro de 1953 e conta hoje com população de 19.840 habitantes (Censo 2010).

O Parque Linear proposto no trabalho de conclusão de curso deverá ser implantado na extensão do córrego Guassu, que está inserido na Área de Proteção Ambiental (APA) da Sub bacia do Rio Pardo na cidade de Bataguassu-MS. Segundo Franco (2008, p.108):

APAs são unidades de conservação destinadas a proteger e conservar a qualidade ambiental e os sistemas naturais ali existentes, viando a melhoria da qualidade de vida da população local e também a proteção dos ecossistemas regionais.

Com a inserção do parque nesta área, o mesmo estaria contribuindo para a cidade e o meio ambiente garantindo que a cidade não cresça no sentido da área de proteção, e proporcionaria aos moradores do município uma área em contato direto com a natureza, incentivando a população a cuidar desse espaço, preservando e protegendo este ambiente, que está sendo esquecido pelos moradores a cada dia.

Porém, o motivo maior da implantação do parque nessa área é que a mesma se encontra próxima a dois novos bairros, sendo um de classe baixa e outro de classe alta, e o crescimento da cidade nesse sentindo é preocupante devido a impactos ao meio ambiente e à própria população que se instala nessas áreas.

O Jardim América III (Figura 1) tem demonstrado processo de expansão territorial em direção ao córrego, apresenta problemas de enchentes e erosões no período de chuvas, cuja água se acumula nessa região.

O difícil acesso da população de baixa renda ás áreas mais centrais das cidades contribuiu para a expansão da periferia, o que muitas vezes implicou, e ainda implica, invasão de áreas de proteção de mananciais, com a aquiescência do poder público. Essa dinâmica agravou a situação de risco dos mananciais, pela eliminação das matas ciliares e conseqüente erosão das margens dos cursos dágua e assoreamento de suas calhas, e pela contribuição do esgoto in natura. (ROLNIK, apud, GORSKI, 2010, p.62) 


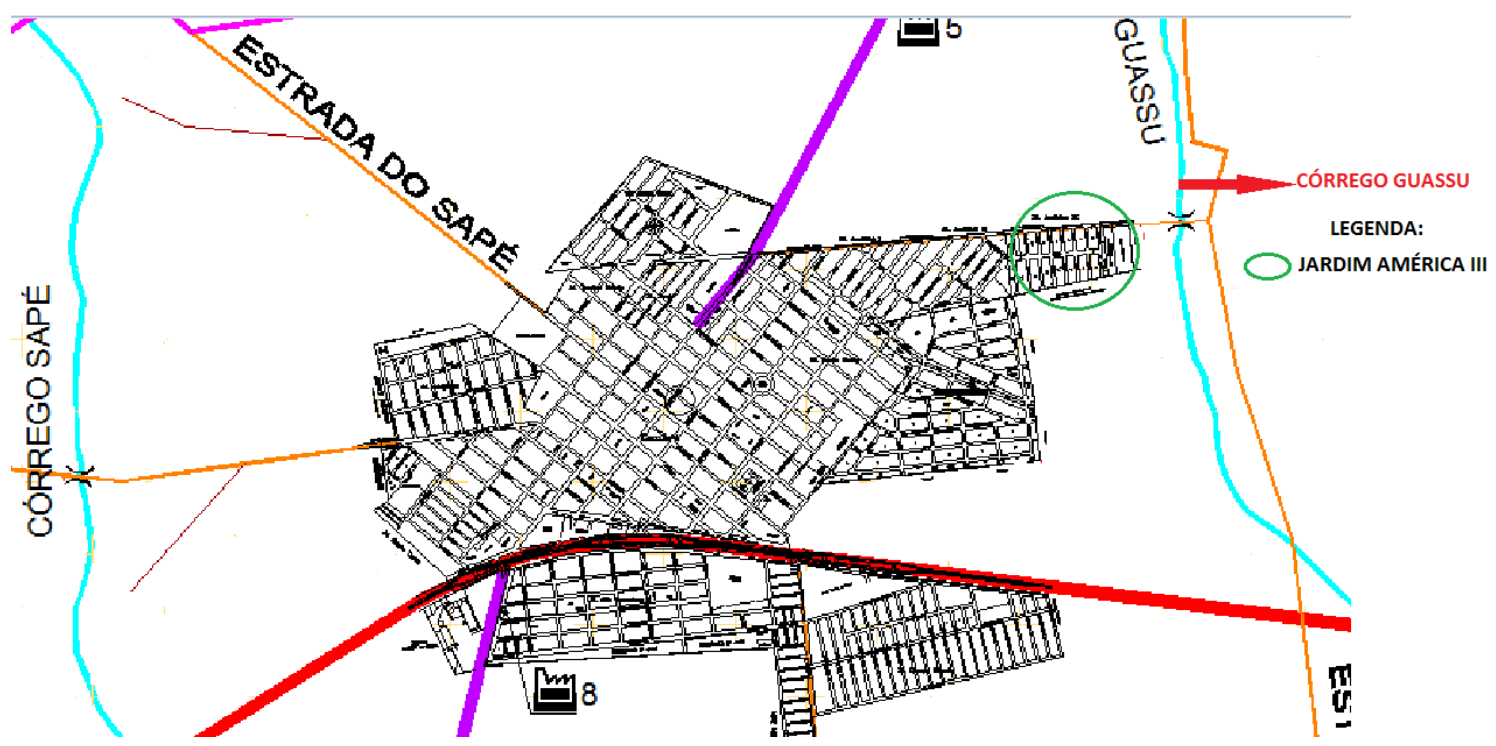

Figura 1. Localização do Jardim América de Bataguassu (Fonte: Prefeitura Municipal de Bataguassu, 2013 modificado pela autora).

Esse descontrole do crescimento da cidade para áreas periféricas gera diversos problemas, as pessoas vão ocupando áreas sem infraestrutura e transformando-as, tomando conta das áreas de preservação e de áreas de risco, sendo que em dias de chuva os problemas se somam, interferindo assim no meio ambiente natural. Como pode ser identificado na planta urbana sobre ponto de alagamento em Bataguassu, elaborada pela Prefeitura Municipal (Figura 2). A área do bairro Jardim América III está apontada como um dos principais pontos de alagamento da cidade.

Assim sendo, a criação do parque linear do córrego Guassu proporcionaria controle de ocupação de novas áreas, auxiliaria no processo de drenagem por manutenção de áreas permeáveis e arborizadas, e ofereceria à população dessa cidade um local de lazer e preservação ambiental adequado. 


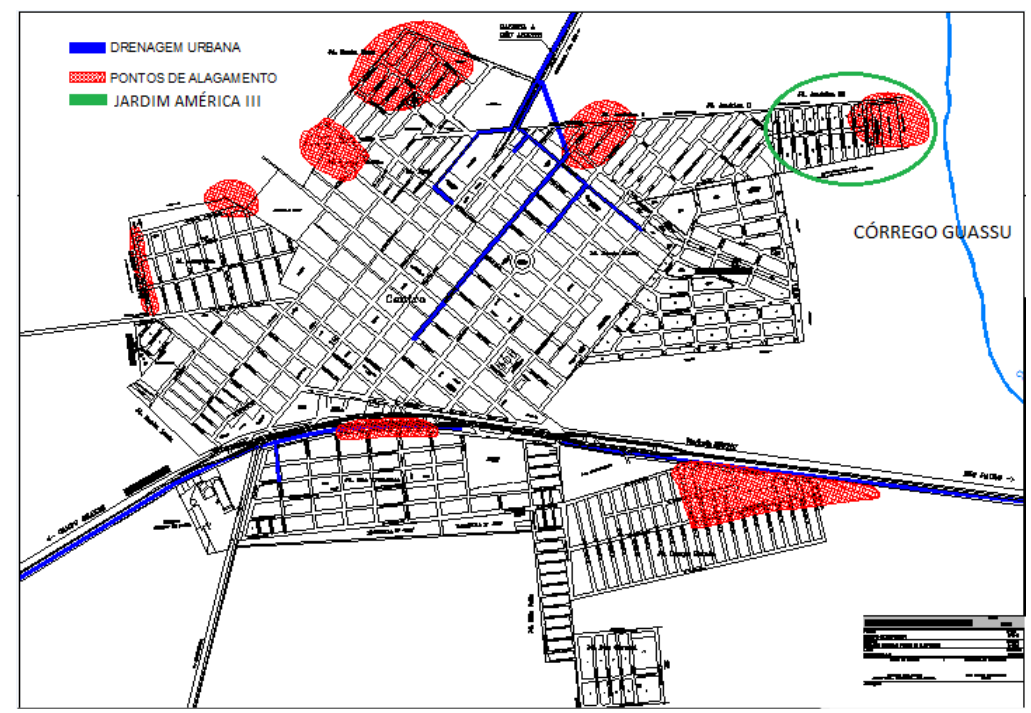

Figura 2. Mapa dos pontos de alagamento de Bataguassu (Fonte: Prefeitura Municipal de Bataguassu-MS, 2013, modificado pela autora).

Tal parque deveria ser divido em faixas (áreas de zoneamento ambiental) conforme mapa a seguir (Figura 3), ou seja, faixa de preservação permanente; faixa para trilhas e ciclovia, de uso não agressivo ao meio ambiente; faixa de equipamentos de lazer, para permanência da população, cuja área apresenta menor fragilidade ambiental; e faixa de recuperação da mata ciliar.
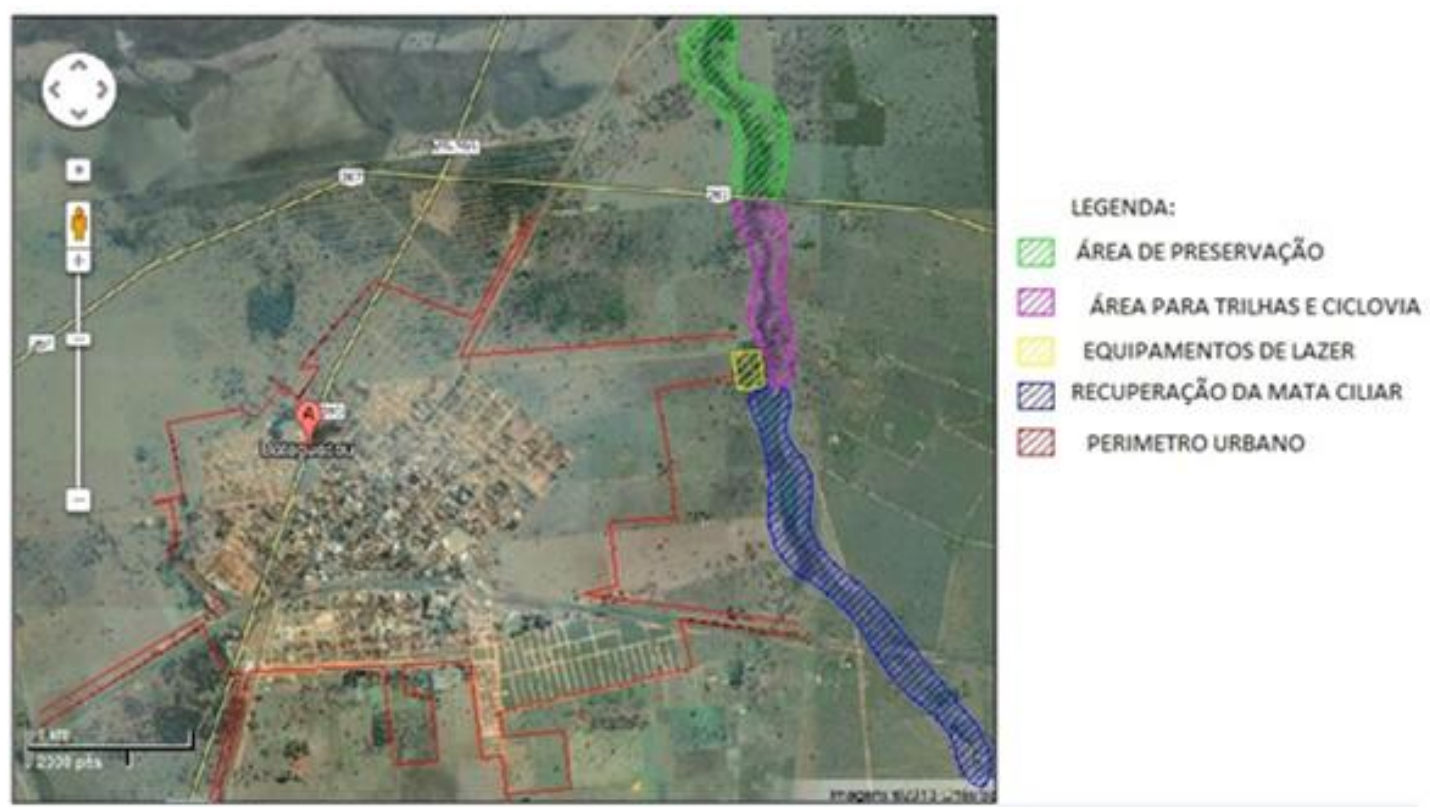

Figura 3. Áreas delimitadas do parque (Fonte: Google Earth 2013, modificado pela autora).

Devido aos levantamentos in loco, foi visto que a nascente do córrego Guassu não possui mais árvores ao seu redor, a mata ciliar foi retirada para ocupação de pastos e reprodução 
de animais das fazendas e sítios na regiãocaracterística que tem se repetido em vários outros pontos, resultando em retirada de quase toda sua vegetação nativa.

Uma das propostas para o projeto seria a recuperação da mata ciliar, que estaria consequentemente recuperando a fauna e a flora do córrego, pois ela é responsável pelo equilíbrio dos rios, garantindo uma boa qualidade da água e de suas margens.

Como observa Gorski (2010, p.45):

A vegetação ao longo dos rios recebe o nome de floresta ou mata ciliar, floresta galeria, mata beiradeira, mata de beira-rio ou mata ripária, e se constitui em fator essencial, como acima mencionado, para sua condição de equilíbrio, e também como fator de atração para o lazer e turismo, pelos aspectos de acolhimento provendo sombra e valor estético. Como habitat da fauna e da flora, as matas ripárias são consideradas ecossistemas muitos ricos pela diversidade de espécies que abrigam.

De acordo com diretrizes de recuperação de matas ciliares desenvolvidas pelo Governo do Estado de São Paulo, é necessário identificar os fatores de degradação do ambiente, e desenvolver atividades educativas ambientais para mostrar para os moradores a importância da recuperação da mata, adotando estratégias ecológicas voltadas para a sustentabilidade do projeto e estabelecer a relação entre o projeto e seus benefícios para rios e córregos e espécies compatíveis para o plantio com o tipo do clima e solo da região do projeto.

A área de equipamentos de lazer do parque linear do córrego do Guassu, aqui proposto, deverá estar localiza em uma área remanescente mais próxima ao Jardim América III (Figura 4), quiosques, churrasqueiras, quadras poliesportivas, playgrounds, academia ao ar livre, espaços para uso livre, centro de apoio ao visitante, banheiros, posto de guarda, com destinação para lazer ativo da população.

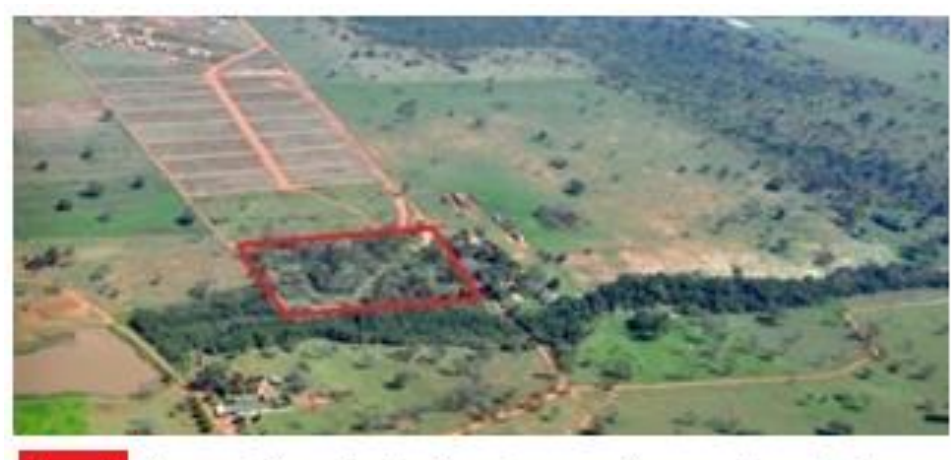

área de implantação dos equipamentos de lazer

Figura 4. Área de equipamentos de lazer (Fonte: Prefeitura Municipal de Bataguassu-MS, 2013, modificado pela autora) 
As áreas para trilhas, ciclovias e pistas de caminhada, deverão estar inseridas onde ainda há uma massa de vegetação nativa, respeitando os 30 de metros de recuo de faixa livre determinadas pelo Código Florestal. E a área denominada aqui de área de preservação ficará da maneira que se encontra, cujo local se localiza mais próximo do rio Pardo, onde o córrego deságua. Esse espaço ainda há presença de boa quantidade de vegetação nativa.

Seguindo conceito de segregação de usos por meio do zoneamento das áreas, busca-se resultado positivo aos propósitos focados, possibilitando um grande ganho pela população urbana desse município.

\section{CONSIDERAÇÕES FINAIS}

O que se buscou com esse a elaboração deste projeto foi amenizar os impactos ambientais que a expansão territorial urbana de Bataguassu-MS poderia desencadear na área do córrego Guassu, além de diminuir os problemas que o bairro Jardim América III já enfrenta em períodos de chuva como erosões e alagamentos. Esse projeto buscou ainda a ligação dos moradores com a natureza, proporcionando atividades de lazer ativo e contemplativo de forma democratizada. O parque busca melhorias tanto para o bairro como para a população urbana em geral, que contaria com espaço adequado de lazer e recreação junto ao verde.

\section{REFERÊNCIAS}

FRANCO, M.A. Desenho Ambiental, uma Introdução á Arquitetura da Paisagem com paradigma ecológico. 2o.ed. São Paulo: Editora Annablume, 2008.

GORSKI, M.C. Rios e Cidades Ruptura e Reconciliação. São Paulo: Editora Senac, 2010.

SILVA, et al. Análises das Características e uso da praça Santo Marconato, Jaboticabal-SP, 2008, Disponível em http://prope.unesp.br/xxi cic/27 35707639861.pdf. Acesso em 15 maio 2013. 